\title{
New Endoscopic Saphenous Vein Harvesting Device (ESVH)
}

\author{
Federico Benetti*1, Natalia Scialacomo ${ }^{1}$ and Gustavo Mazzolino ${ }^{2}$ \\ ${ }^{1}$ Department of Cardiac Surgeon, Argentina \\ ${ }^{2}$ Department of Endoperfect Technical support, Argentina
}

Received: May 05, 2018; Published: May 11, 2018

*Corresponding author: Federico Benetti, Department of cardiac surgeon, Benetti Foundation, Rosario, Santa Fe, Alem 1846 Argentina

Abbreviations: SV: Saphenous Vein; EVH: Endoscopic Saphenous Vein Harvester

\section{Introduction}

The EndoPerfect system is indicated for minimally invasive surgery and for the removal of blood vessels via video-assisted endoscopic technique. In particular, it is indicated for the removal of the Saphenous Vein (SV) and subsequently used for aortacoronary bypass, for the removal of the radial artery or for bypass operations of peripheral blood vessels. This type of Endoscopic Saphenous Vein Harvester (EVH) has been utilized for more than 20 years in varying different models, gaining a great deal of experience worldwide [1-4]. As we start removing the Saphenous Vein with the "no touch" fundamental, using the Endoscopic technique, we are seeing a great potential of this device for performance and much more advantageous than the competing devices in today's market. The EndoPerfect has a different tunneling approach into the leg, offering better control and mobility inside the working channel without the need of using $\mathrm{CO}_{2}$ [5-6].

\section{Device Description}

The system consists of three 3 independent instrument tools and the capability to maneuver all of them with versatility and

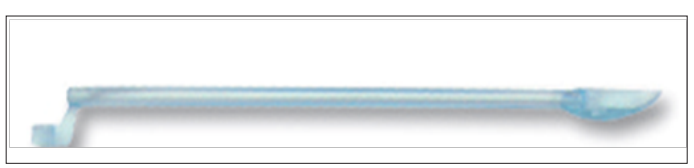

Figure 1: Initial instrument used to tunnel the leg, creating the channel to begin exposing the SV and for dissecting the vein.

Tunneling/Dissector: Initial instrument used to tunnel the leg, creating the channel to begin exposing the SV and for dissecting the vein. An optic (Laparoscope, $30 \mathrm{~cm}, 30^{\circ}$ angle) will be needed to illuminate and see the wound/channel area. A very friendly in strument, suitable for multiple leg approaches. Once the tunnel and dissection is performed, this device is retrieved from the leg and replaced by the Spacer/Dissector (Figure 1).

Spacer/Dissector: Instrument placed into the already dissected vessel and will control the tunnel and position of the SV, providing bedding and resting area for the SV conduit. This larger device will be used as the main spacer and channel exposer, with the possibility to have a larger view and space to retrieve the SV as well to evacuate the smoke left by cutting and cauterizing the SV side branches (Figure 2).

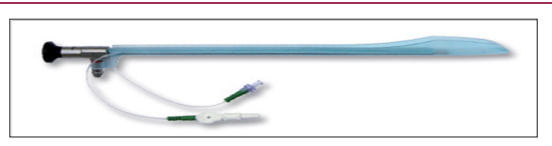

Figure 2: Instrument placed into the already dissected vessel and will control the tunnel and position of the SV, providing bedding and resting area for the SV conduit.

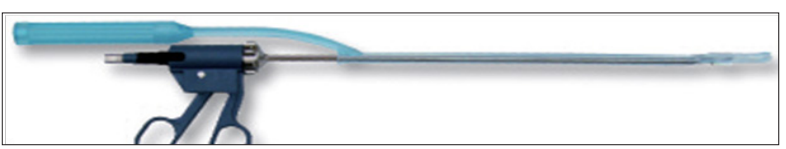

Figure 3: Instrument mounted independently on top of the Spacer/Dissector from above, offering the freedom to manipulate the SV harvesting and brunch cutting.

Manipulator: Instrument mounted independently on top of the Spacer/Dissector from above, offering the freedom to manipulate the SV harvesting and brunch cutting, preserving the fat for better nutrients of the SV endothelium This part will be the one wich the Bipolar Blunt scissors will be mounted and the one that will manipulate and free the vein from the remaining anatomy. 
A bipolar scissor with standard RF energy or Harmonic energy can be used as coagulation and cutting device (Figure 3).

\section{Conclusion}

After using the EVH Endoperfect we found this system friendly and efficient, particularly when taking the complete SV, using the "no touch SV Harvesting" technique. [6], considering the EVH an optimum device to act in accordance with the "no touch SV Harvesting Technique".

The overall advantage of this device:

a) The distal end tip from where the SV will be guided and handled is wider which then provides for a better opening when retrieving enough surrounding fat.

b) No need for the use $\mathrm{CO}_{2}$.

Although this device have been used in more then 200 cases, more experience is needed to validate these observations, as well to determinate the efficiency of the SV as "no touch surgical harvesting".

This work is licensed under Creative Commons Attribution 4.0 License

Submission Link: https://biomedres.us/submit-manuscript.php

\section{References}

1. Allen KB, Shaar CJ (1997) Endoscopic saphenous vein harvesting. Ann Thorac Surg 64(1): 265-266.

2. Nezafati P, Kahrom M, Nezafati MH (2017) Endoscopic vein harvesting: the growing role in cardiac surgery. Arch Med Sci Atheroscler Dis 2: 3436.

3. Ferdinand FD, Mac Donald JK, Balkhy HH, Bisleri G, Hwang HY, et al. (2017) Endoscopic Conduit Harvest in Coronary Artery Bypass Grafting Surgery: AnISMICS Systematic Review and Consensus Conference Statements. Innovations (Phila) 12(5): 301-319.

4. Krishnamoorthy B, Critchley WR, Thompson AJ, Payne K, Morris J, et al. (2017) Study Comparing Vein Integrity and Clinical Outcomes in Open Vein Harvesting and 2 Types of Endoscopic Vein Harvesting for Coronary Artery Bypass Grafting: The VICO Randomized Clinical Trial (Vein Integrity and Clinical Outcomes). Circulation 136(18): 1688-1702.

5. Suarez Pierre A, Terasaki Y, Magruder JT, Kapoor A, Grant MC, et al. (2017) Complications of $\mathrm{CO}_{2}$ insufflation during endoscopic vein harvestin0067. J Card Surg 32(12): 783-789.

6. Dashwood MR, Savage K, Tsui JC, Dooley A, Shaw SG, et al. (2009) Retaining perivascular tissue of human saphenous vein grafts protects against surgical and distension-induced damage and preserves endothelial nitric oxide synthase and nitric oxide synthase activity. J Thorac Cardiovasc Surg 138(2): 334-340.

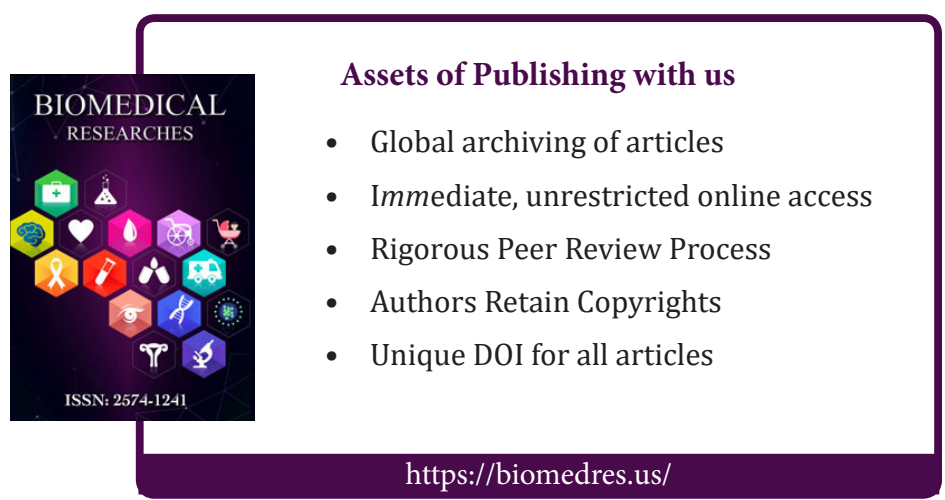

